Шарифов А.Р., Санкт-Петербургский горный университет,

Мардашов Д.В. Санкт-Петербург, Россия

\title{
ИЗУЧЕНИЕ ПРОЦЕССА ВЫТЕСНЕНИЯ СВЕРХВЯЗКОЙ НЕФТИ ИЗ МОДЕЛИ ТРЕЩИННОЙ КАРБОНАТНОЙ ПОРОДЫ УГЛЕВОДОРОДНЫМИ РАСТВОРИТЕЛЯМИ
}

Введение

Материаль и методы:

Результать исследований

Обсуждение и заключение:

Ключевые спова: ввиду невысокой скорости реакции растворителей с нефтью при пластовой температуре, их закачку необходимо комбинировать с применением теплоносителей. Очередность закачки растворителя и теплоносителя зависит от геолого-физических свойств изучаемого объекта. В данной работе изучен механизм интенсификации добычи сверхвязкой нефти из карбонатной породы с единичной трещиной закачкой углеводородных растворителей при различных температурах и расходах.

Проведены реологические исследования с дозированием различных растворителей. В качестве объекта исследований испопьзованы образцы устьевых проб сверхвязкой нефти и карбонатный керн одного из месторождений Самарской области. Для изучения влияния температуры и расхода закачиваемого угпеводородного растворителя, керны перед начапом фильтрационных исспедований были распилены пополам с целью моделирования продольной трещины. В качестве рассматриваемых растворителей использовались как химические композиции, так и индивидуальные вещества.

получены зависимости динамической вязкости нефрти от типа и концентрации растворителя для температур $20-70^{\circ} \mathrm{C}$. Экспериментально определены зависимости коэффициента вытеснения нефти от температуры и расхода закачиваемого растворителя для модели породы-пласта с единичной трещиной. Проведены расчеты, отражающие механизм добычи нефти (диффузионный/конвективный), при закачке растворителя. Аналитически рассчитана глубина проникновения растворителя в матрицу пласта в зависимости от времени выдержки растворителя и температуры пласта.

на основе анапитических расчетов обоснована низкая эффективность закачки растворителей при пластовой температуре из-за необходимости продолжительного времени выдержки на диффузионный обмен. Для усповий изучаемого объекта предложена методика закачки растворитепя и его состав.

нефть сверхвязкая; растворители углеводородные; диффузия; реология нефти; интенсификация притока. 
Sharifov A.R. St. Petersburg mining University,

Mardashov D.V. St. Petersburg, Russia

Introduction:

Materials

and methods:

Results:

Discussion and conclusion

Keywords:

\section{Research the process of displacing heavy oil by hydrocarbon solvents from a model of fractured carbonate core}

due to the low rate of solvents reaction with heavy oil at the reservoir temperature, solvent injection must be combined with thermal fluids. Solvent and thermal fluids injection order depends on reservoir geological and physical properties. The mechanism of heavy oil intensification from carbonate rock with single fracture by injection of solvents at various temperature and rate has been studied in this paper.

The rheological property of the heavy oil with solvents has been studied. Heavy oil samples and carbonate core of one field from Samara Region used as an object of research. For simulate longitudinal fracture the core has been cut before filtration experiments. Chemical compositions and individual substances were used as solvents.

The dependences of the heavy oil dynamic viscosity on the type and concentration of solvent for temperatures $20-70^{\circ} \mathrm{C}$ has been defined. The dependences of the oil recovery factor on the system temperature and injected solvent flow rate for model of carbonate rock with single fracture has been experimentally determined. The mechanism of oil production (diffusion/ convective) during solvent injection has been calculated. Analytically calculated solvent penetration depth into the matrix depending on the time and the temperature of the core.

on the basis of analytical calculations, the low efficiency of solvent injection at reservoir temperature has been justified due to the need long time for diffusion exchange. For the studied reservoir properties method for solvent injection and its composition have been proposed.

heavy oil, solvents, diffusion, oil rheology, oil production intensification.

\section{Введение}

Одним из наиболее широко применяемых методов интенсификации добычи сверхвязкой нефти (с динамической вязкостью в пластовых условиях более 200 мПа с) является применение растворителей. Объектами воздействия растворителей являются скважина, призабойная зона или весь продуктивный пласт. В зависимости от объекта воздействия может происходить вымывание мелких частиц твердой фазы, разбавление нефти, растворение отложений тяжелых компонентов нефти и разрушение водонефтяных эмульсий. Методы, связанные с обработкой скважины, нацелены на уда- 
ление органических отложений и эмульсий типа «вода в нефти» и дают кратковременный эффект. Для повышения эффективности обработок необходимо глубокое продавливание растворителя в призабойную зону пласта. Механизм интенсификации, в данном случае, основывается на взаимодействии закачиваемого агента с нефтью и ее разбавлении вдали от забоя скважины.

Основным недостатком растворителей является невысокая скорость реакции с нефтью. Численным показателем скорости реакции является коэффициент диффузии. Для повышения скорости реакции растворители используют в комплексе с термическими методами добычи нефти: закачивают перед или после теплоносителя, либо дозируют непосредственно в него. При дозировании растворителя в пар или горячую воду он служит дополнительным источником снижения вязкости нефти. В таком случае, необходимо особое внимание уделять процессу подбора растворителя при его дозировании в пар: для предотвращения преждевременной конденсации веществ их температуры парообразования и конденсации должны быть схожи.

После теплового воздействия происходит изменение компонентного состава добываемой нефти в сторону увеличения содержания тяжелых компонентов. С увеличением температуры увеличивается молекулярный вес остаточных углеводородов в пласте. Наиболее тяжелые компоненты сосредотачиваются в призабойной зоне пласта (ПЗП), в результате, их растворение сопровождается чередой осложнений от невозможности подбора химических композиций до их транспортирования на забой.

При закачке растворителя перед теплоносителем, за счет разбавления нефти и растворения тяжельх компонентов, снижается градиент давления закачки последнего. Как уже было сказано ранее, в таком случае процесс диффундирования занимает продолжительное время. Для ускорения данного процесса используют газообразные предельные углеводороды [1], в результате чего происходит осаждение асфальтенов в пласте. Во избежание отложений асфальтенов в состав растворителя должны быть включены высококипящие ароматические углеводороды. В таком случае, единственным способом ускорить процесс диффузии является предварительный прогрев пласта.

По мнению авторов работы, мало изучены процессы добычи сверхвязкой нефти из трещинно-поровых карбонатных коллекторов с применением растворителей. В частности, особый интерес представляет влияние технологических процессов закачки растворителя (расход, температура) на степень извлечения нефти. Основным механизмом добычи нефти из таких коллекторов является массоперенос между матрицей и трещиной.

С целью изучения процесса интенсификации притока из трещинного карбонатного пласта были поставлены следующие задачи:

1. Подобрать наиболее эффективный растворитель для условий залегания изучаемого объекта на основе реологических и физико-химических исследований. 
2.

Провести фильтрационные исследования на модели керна с продольной трещиной при разных расходах закачиваемого растворителя и температуре системы.

3. Предложить технологию закачки растворителя для условий залегания изучаемого объекта.

\section{Материалы и методы \\ исследований}

Для исследований использовалась дегазированная, обезвоженная нефть одного из месторождений Самарской области. Зависимость коэффициента динамической вязкости нефти от температуры отражена на рисунке 1 . Содержание асфальтенов, смол и парафинов в нефти $-12,4 \%, 9,4 \%$ и $4,7 \%$ соответственно.

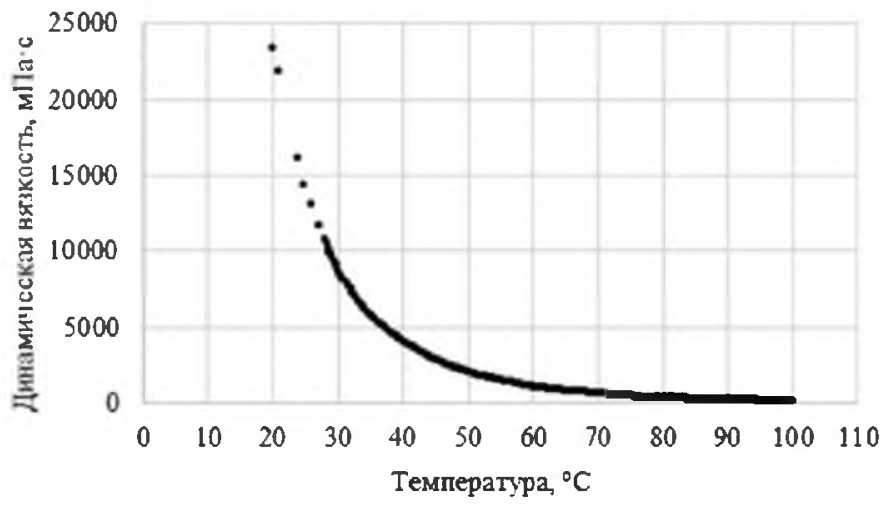

Рис. 1.

Зависимость коэффициента динамической вязкости исследуемой нефти от температуры.

Fig. 1. The dependence of the studied oil dynamic viscosity coefficient from temperature.

В качестве изучаемых растворителей были использованы следующие химические композиции и индивидуальные вещества:

алифатические углеводороды с температурой кипения $68^{\circ} \mathrm{C}$ (гексан);

смесь легких алифатических углеводородов с интервалом температуры кипения $70-100{ }^{\circ} \mathrm{C}$ (эфир петролейный); ароматические углеводороды $\mathrm{c}$ температурой кипения $144{ }^{\circ} \mathrm{C}$ (орто-ксилол);

смесь углеводородов с интервалом температур кипения $150-250{ }^{\circ} \mathrm{C}$ (керосин ТC-1). 
Эксперименты проводились на образце карбонатной породы, который предварительно был распилен на две равные части для моделирования трещины. Открытая пористость керна по гелию $25 \%$, абсолютная проницаемость пористой части по гелию 0,5 мкм². Диаметр керна $3 \mathrm{~cm}$, длина была ограничена возможностыю кернодержателя и равнялась $10 \mathrm{cм}$. Проводимость трещины была рассчитана на основе определения ее геометрических размеров: ширина трещины 2,6 см; раскрытость трещины $0,1 \mathrm{~cm}$.

Пластовое давление изучаемого объекта составляет 8,5 МПа, начальная нефтенасыщенность кернов $100 \%$; температура $28^{\circ} \mathrm{C}$.

\title{
Методика проведения реологических исследований
}

Значения коэффициента динамической вязкости нефти с добавлением растворителей определялись на ротационном вискозиметре Anton Paar MCR 102 с измерительной системой плита/плита (рис. 2).

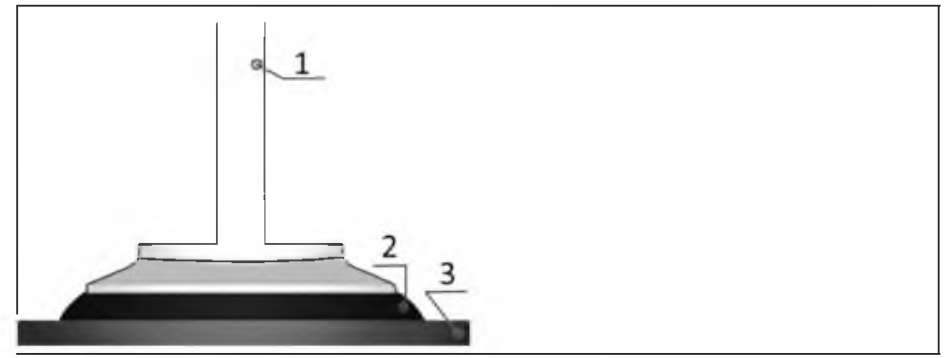

Pиc. 2.

\author{
Модель измерительной системы: \\ 1 - измерительная система; \\ 2 - образец; \\ 3 - нагреваемая плита. \\ Fig. 2. The model of the measuring system: 1 - measuring system; \\ 2 - sample; 3 - heated plate.
}

Исследования проводились при скорости сдвига 3c-1, которая соответствует реально возможной линейной скорости фильтрации в трещине. Конщентрация растворителя в составе нефти составляла $5 ; 10 ; 15$; $20 ; 25(30) \%$, соответственно. Для проведения реологических исследований изучаемый растворитель предварительно смешивался с нефтыю в емкости из кварцевого стекла. Образцы разово приготавливались непосредственно перед проведением испытаний.

\section{Методика по определению количества}

осажденных асфальтенов

Для уточнения минимальной допустимой концентрации ароматических углеводородов в составе растворителя были проведены ис- 
следования по определению количества осажденных асфальтенов по стандарту ASTM D2042-97 [2]: 1 г нефти разбавлялся в 100 мл исследуемого растворителя с дальнейшей фильтрацией через фильтровальную бумагу. Далее фильтр помещался в печь для сушки на 24 часа при температуре $105^{\circ} \mathrm{C}$. Фильтр с остатком взвешивался и определялся процент осажденных асфальтенов по формуле:

$$
\mathrm{A}=\frac{M_{\text {ocr. } \phi}-M_{\phi}}{M_{\mathrm{B}}} \cdot 100 \%,
$$

$M_{\text {ocr.ф }} \quad$ масса остатка с фильтром, г;

$M_{\phi}-\quad$ фильтра, г;

$M_{\text {н }}$ - начальная масса нефти, г.

\section{Методика проведения фильтрационных исследований}

1. Подготовка керна

Процесс подготовки керна был начат с проточного экстрагирования содержавшихся флюидов керосином. Далее керн был распилен пополам, а для насыщения нефтью помещен в кернодержатель с созданием давления обжима 3 МПа. В промежутки между кернами предварительно была помещена резиновая прокладка для предотвращения прорыва нефти из трещины. Из-за высокой вязкости нефти температура термошкафа поддерживалась равной $50^{\circ} \mathrm{C}$. После закачки 2 поровых объемов нефти при скорости фильтрации 0,5 мл/мин процесс насыщения прекращался, температура в системе снижалась до $28^{\circ} \mathrm{C}$, а керны взвешивались и определялась их насыщенность нефтью. После определения нефтенасыщенности керны соединялись, а в промежутки между ними помещались металлические стержни толщиной 0,1 см таким образом, чтобы собранная система моделировала процесс добычи нефти из матричной системы с единичной трещиной

\section{2. Закачка растворителя}

Фильтрационные исследования проводились на установке, оснашённой насосом (1), накопителями для нефти (2) и растворителя (3), кернодержателем (4), системой противодавления (5), градуированной мерной ёмкостью (6) и обратным клапаном (7) (рис. 3). Элементы установки №o2, 3,4, и 7 были помещены в термошкаф для обеспечения постоянной заданной температуры.

Закачка растворителя велась в режиме постоянного расхода. Объем закаченного растворителя составлял 500 мл, что соответствовало 7 поровым объемам. Такое количество закачиваемого растворителя обусловлено необходимостью моделирования призабойной зоны пласта, через которую фильтруется вся масса реагента. Для определения доли нефти в выходной продукции 


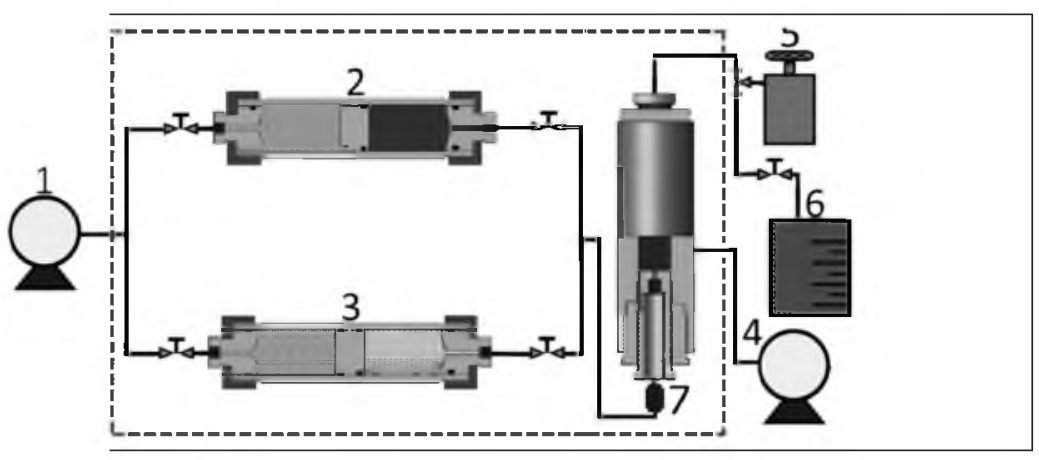

Рис. 3.

Схема фильтрационной установки.

Fig. 3. Filtration equipment scheme.

определялась плотность полученной смеси и сопоставлялась с заранее определенными значениями при известных концентрациях растворителя. Во избежание гравитационного вытеснения нефти, кернодержатель располагался вертикально, направление фильтрации снизу-вверх. Давление обжима соответствовало $10 \mathrm{MПа,} \mathrm{а} \mathrm{противодавление} \mathrm{в} \mathrm{системе} \mathrm{-} \mathrm{8,5} \mathrm{МПа.}$

\section{Результаты исследований и их обсуждение}

Первым этапом исследований было изучение влияние типа углеводородного растворителя на степень снижения вязкости нефти. В исследованиях использовались растворители алифатического ряда (гексан, петролейный эфир фракции 70-100) и ароматические углеводороды (о-ксилол).

Было установлено, что при температурах $20-28{ }^{\circ} \mathrm{C}$ вязкость нефти с добавлением петролейного эфира, представляющего собой смесь алифатических углеводородов, ниже, чем при в смесях с однокомпонентными растворителями. С увеличением температуры нет значительной разности в вязкости нефти при разбавлении ее различными по типу растворителями (см. рис. 4). При добавлении гексана и петролейного эфира в концентрации свыше $15 \%$ наблюдалось повышение значений динамической вязкости смеси. Это косвенно свидетельствует об осаждении тяжелых компонентов из нефти, влияющих на ее вязкость.

По результатам исследований по определению количества осажденных асфальтенов было установлено, что минимально допустимая доля ароматических углеводородов в составе комплексного растворителя для изучаемой нефти составляет 20\%. При уменьшении концентрации о-ксилола наблюдается скачкообразное увеличение осадка (см. рис. 5).

Среди растворителей, нашедших широкую промышленную применимость, можно использовать керосин марки ТC-1, с содержанием ароматичес- 


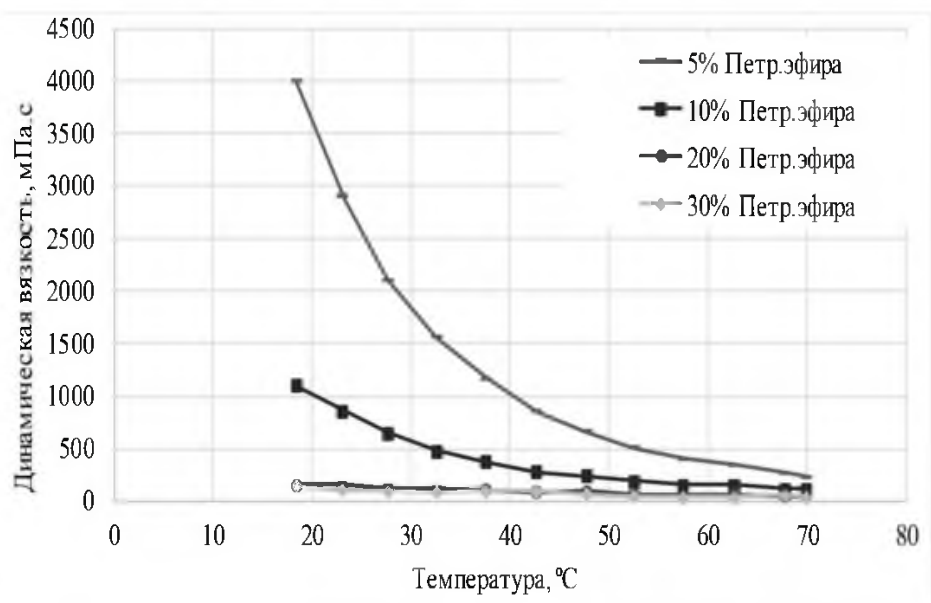

б
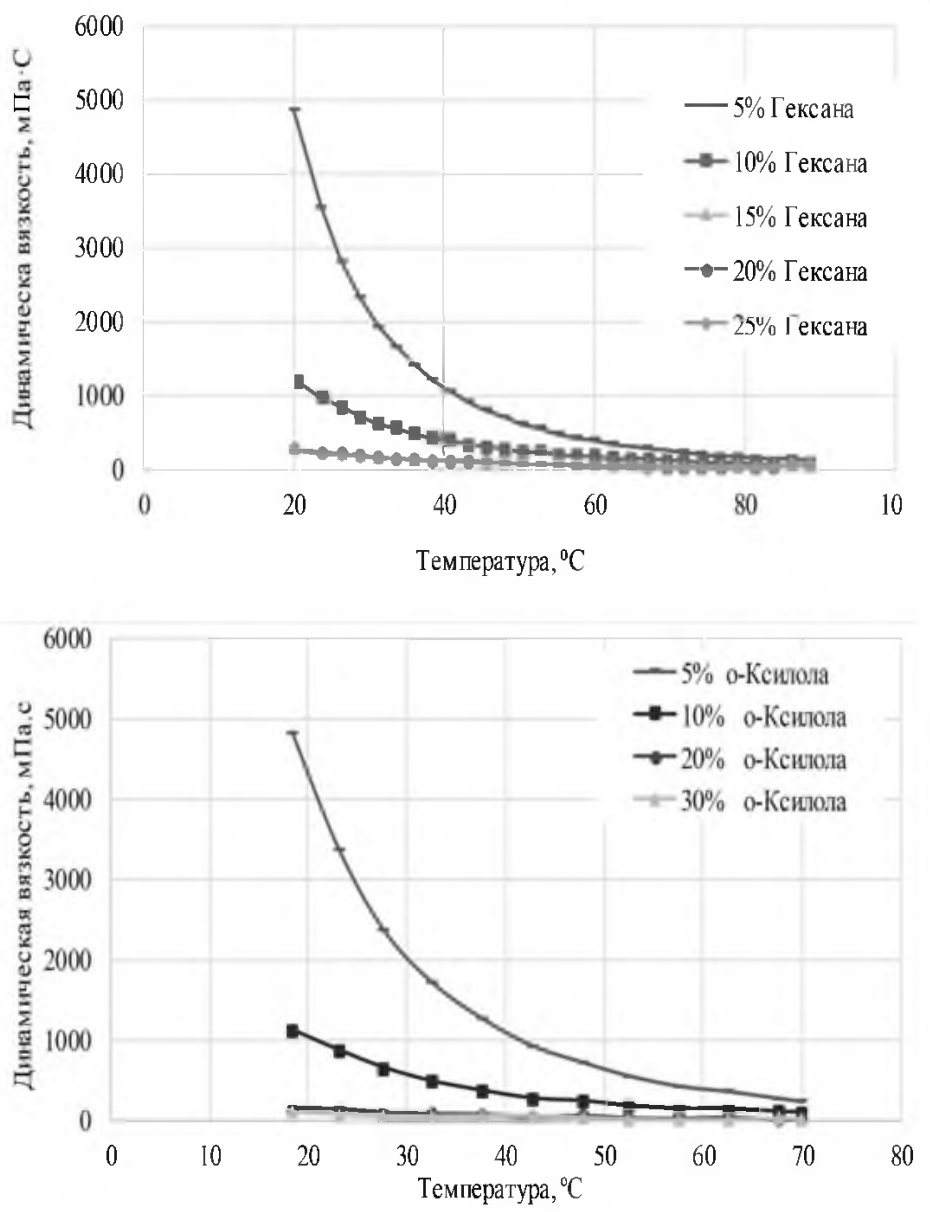

Рис. 4.

Результаты определения вязкости нефти при дозировании растворителей в температурном диапазоне $20-70{ }^{\circ} \mathrm{C}$.

Fig. 4. Results of oil viscosity with solvent determining in the temperature range of $20-70{ }^{\circ} \mathrm{C}$ 


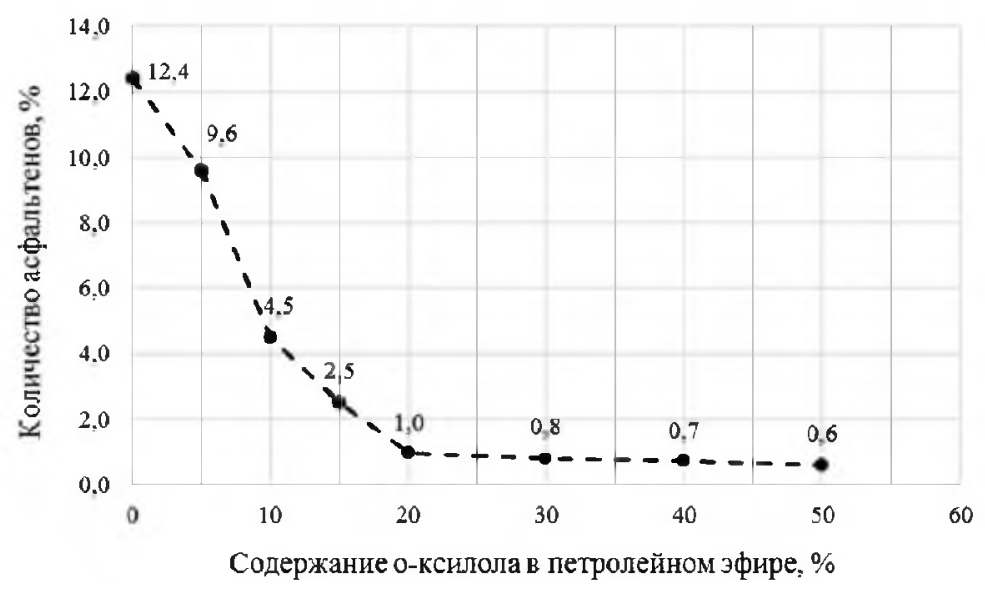

Рис. 5.

Зависимость количества осажденных от содержания 0-ксилола в составе петролейного эфира.

Fig. 5. The dependence of the asphaltene precipitatate amount and xylene content in the petroleum ether composition

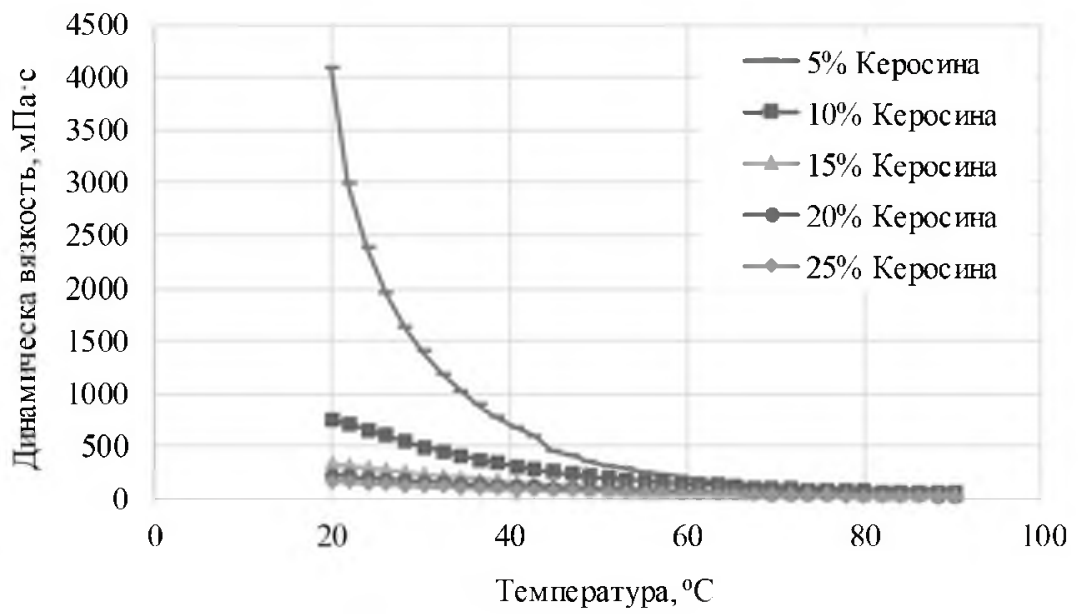

Pиc. 6.

Зависимость вязкости нефти от содержания керосина марки ТС-1.

Fig. 6 The dependence of oil viscosity from kerosene content.

ких углеводородов в составе не более $22 \%$. Зависимость вязкости нефти от температуры при различной концентрации керосина показана на рисунке 6 .

На рисун ке 7 представлены результаты определения коэффициента вытеснения нефти из керна с продольной трещиной при температурах в системе $28,50,75$ и $100{ }^{\circ} \mathrm{C}$ и расходах керосина 0,$25 ; 0,5,1$ и 5 мл/мин в разные моменты времени.

Как видно из рисунков при увеличении расхода керосина наблюдается уменьшение коэффициента вытеснения нефти при одинаковых объемах за- 


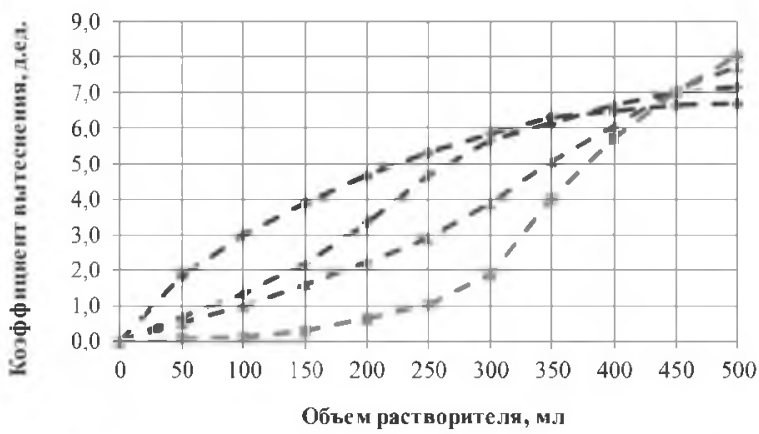

$\multimap 0,25 \mathrm{MJ} / \mathrm{Mин}-\bullet 0,5 \mathrm{MJ} / \mathrm{MuH}-\downarrow 1 \mathrm{M} / \mathrm{MuH}-5 \mathrm{Mr} / \mathrm{MuH}$

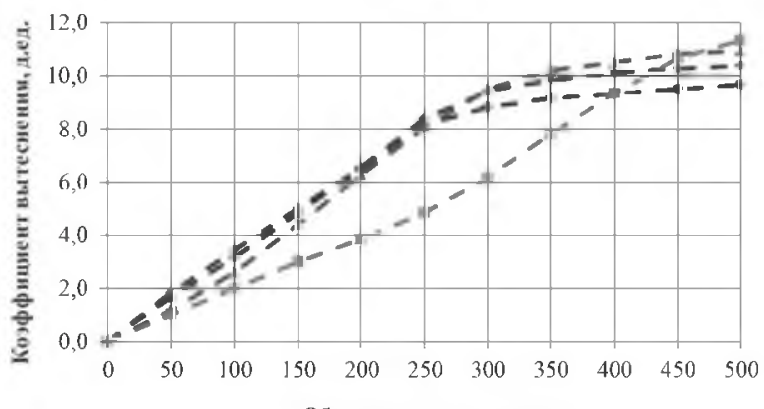

Объем растворителя, мл

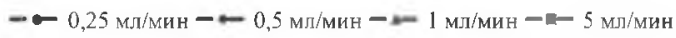

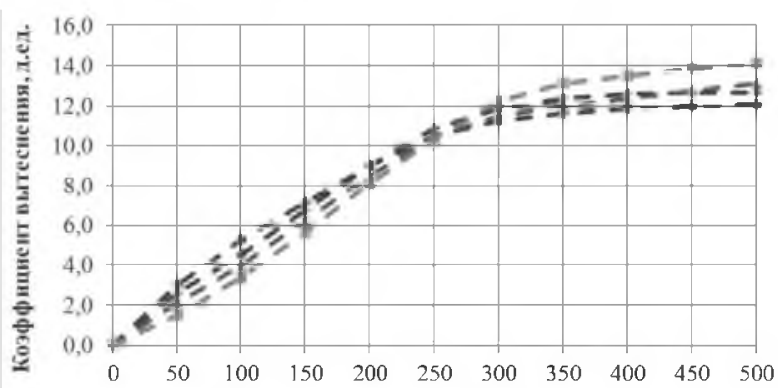

Объъем раст ворителя, мл

B

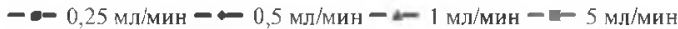

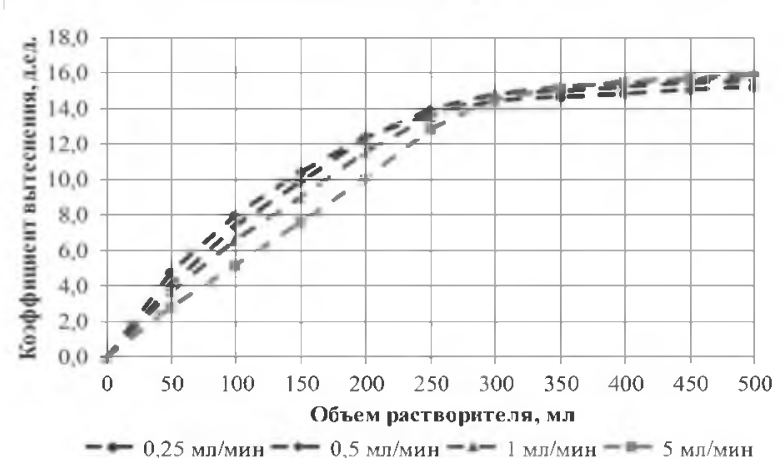

Pис. 7.

Зависимости коэффициента вытеснения нефти от объема закаченного растворителя при разных расходах: а - температура $28^{\circ} \mathrm{C}$; 6 - температура $50^{\circ} \mathrm{C}$; в - температура $75^{\circ} \mathrm{C}$; г- температура $100^{\circ} \mathrm{C}$.

Fig. 7. Dependence of oil displacement from injected solvent volume at different rates: $a-$ temperature $28^{\circ} \mathrm{C} ; \sigma$ - temperature $50^{\circ}$ $\mathrm{C}$; B - temperature $75^{\circ} \mathrm{C}$; $\mathrm{r}$ - temperature $100^{\circ} \mathrm{C}$ 
Таблица 1.

РЕЗУЛЬТАТЫ РАСЧЕТОВ КОЭФФИЦИЕНТА ДИФФУЗИИ

Table 1. Calculation results of diffusion constant

\begin{tabular}{l|l|l|l|l}
\hline $\begin{array}{l}\text { Tемпература, } \\
{ }^{\circ} \mathbf{C}\end{array}$ & $\begin{array}{l}\text { Молекулярная } \\
\text { масса нефти, } \\
\text { г/моль }\end{array}$ & $\begin{array}{l}\text { Вязкость } \\
\text { керосина, } \\
\text { мПасс }\end{array}$ & $\begin{array}{l}\text { Мольный объем } \\
\text { растворителя, } \\
\text { мл/моль [6] }\end{array}$ & $\begin{array}{l}\text { Коэффициент } \\
\text { диффузии, } \\
\text { см }{ }^{2} / \mathbf{c}\end{array}$ \\
\hline 28 & 151,2 & 1,3 & 515.2 & $4,94 \cdot 10-6$ \\
\cline { 3 - 5 } & & 1,04 & 521 & $6,8 \cdot 610-6$ \\
\hline 75 & & 0,74 & 527.8 & $9,89 \cdot 10-6$ \\
\hline 100 & & 0,545 & 534.7 & $1,44 \cdot 10-5$ \\
\hline
\end{tabular}

Таблица 2

\section{ЗНАЧЕНИЯ ЧИСЛА ПЕКЛЕ ПРИ РАЗНЫХ ТЕМПЕРАТУРАХ} И СКОРОСТЯХ ФИЛЬТРАЦИИ

Table 2. Peclet number values at different temperatures and filtration rates

\begin{tabular}{|c|c|c|}
\hline Температура, ${ }^{\complement C}$ & Объемный расход, мл/мин & Число Пекле \\
\hline \multirow{4}{*}{28} & 0,25 & 11,9 \\
\hline & $\overline{0,5}$ & 23,9 \\
\hline & $\overline{1}$ & 47,7 \\
\hline & 5 & 238,7 \\
\hline \multirow{4}{*}{50} & 0,25 & 8,6 \\
\hline & 0,5 & 17,2 \\
\hline & $\overline{1}$ & 34,4 \\
\hline & $\overline{5}$ & 171,9 \\
\hline \multirow{4}{*}{75} & 0,25 & 6,0 \\
\hline & $\overline{0,5}$ & 11,9 \\
\hline & $\overline{1}$ & 23,8 \\
\hline & 5 & 119,2 \\
\hline \multirow{4}{*}{100} & 0,25 & 4,1 \\
\hline & $\overline{0,5}$ & 8,2 \\
\hline & $\overline{1}$ & 16,4 \\
\hline & $\overline{5}$ & 82,1 \\
\hline
\end{tabular}

качки растворителя. При увеличении объемов закаченного растворителя конечный коэффициент вытеснения нефти растет. Это связано с тем, что при увеличении скорости также увеличивается глубина проникновения керосина. В начальный момент времени коэффициент вытеснения заметно выше с уменьшением расхода закачиваемого растворителя, что связано со спецификой проведения эксперимента: из-за наличия системы противодавления тре- 

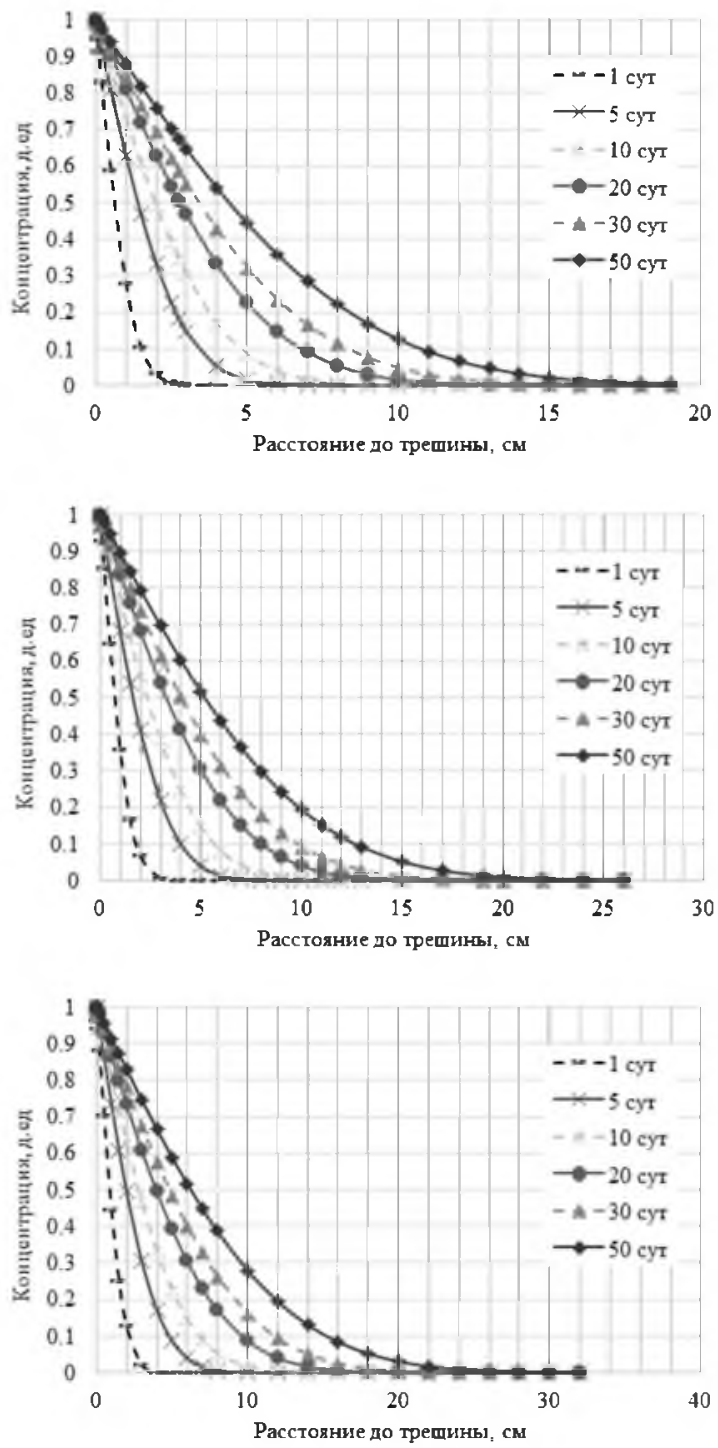

B

Расстояние до трешины, см

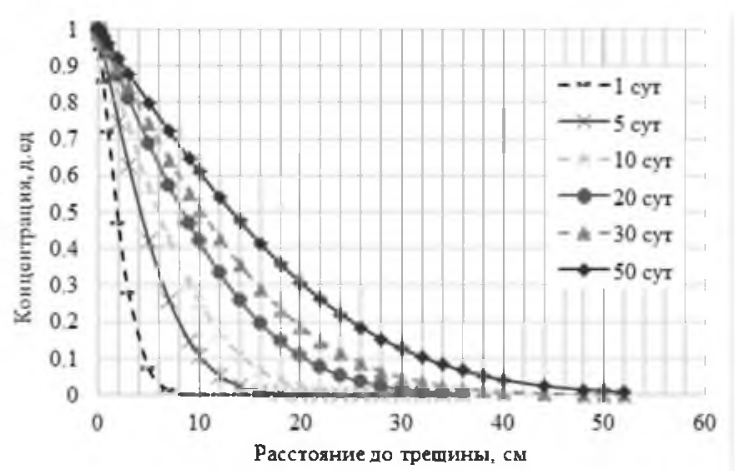

Рис. 8.

Распределение концентрации растворителя в зависимости от расстояния до трещины:

а - температура $28{ }^{\circ} \mathrm{C} ;$ б - температура $50{ }^{\circ} \mathrm{C}$; в - температура $75^{\circ} \mathrm{C}$; г - температура $100^{\circ} \mathrm{C}$

Fig. 8. Depending of the distribution solvent concentration from distance to the fracture: a - temperature $28^{\circ} \mathrm{C} ; 6$ - temperature $50^{\circ} \mathrm{C} ; \mathrm{B}-$ temperature $75^{\circ} \mathrm{C}$; $\left\ulcorner\right.$ - temperature $100^{\circ} \mathrm{C}$ 
буется больше времени для достижения давления прорыва при мальх расходах, в результате чего растворитель находится в контакте с керном дольше.

При повышении температуры в кернодержателе также увеличивается коэффициент вытеснения нефти: при повышении температуры с 28 до $50^{\circ} \mathrm{C}$ в среднем на $1,4 \%$; до $75^{\circ} \mathrm{C}$ - на $3,7 \%$; до $100^{\circ} \mathrm{C}$ - на $6,8 \%$, соответственно.

С увеличением расхода закачиваемого растворителя изменяется характер вытеснения нефти: при расходе 0,25 мл/мин наблюдается равномерное вытеснение нефти под воздействием диффузионных сил. При повышении скорости закачки преобладает конвективный характер вытеснения нефти растворителем. Численным показателем, отражающим характер вытеснения, является критерий подобия Пекле [3]

$$
N_{P e}=\frac{v \cdot b}{m \cdot D}
$$

$v$ - $\quad$ линейная скорость фильтрации, м/с;

$b$ - $\quad$ раскрытость трещины, м;

$m-\quad$ пористость, д.ед.;

$D$ - $\quad$ коэффициент диффузии, $\mathrm{M}^{2} / \mathrm{c}$.

При значении числа Пекле менее 1 можно учитывать только диффузионных силы при вытеснении нефти, а при значениях выше 1 пренебрежение конвективным механизмом ошибочно [4].

На основе уравнения Wilke-Chang [4], которое является модификацией уравнения Стокса-Эйнштейна можно определить коэффициент диффузии растворителя в нефть, однако в качестве растворимого вещества следует принять керосин, в качестве растворителя - нефть:

$$
D=\frac{7,4 \cdot 10^{-8} \cdot M^{0,5} \cdot T}{\mu_{\mathrm{n}} \cdot V^{0,6}}
$$

$D-\quad$ коэффициент диффузии, $\mathrm{cm}^{2} / \mathrm{c}$;

$M-\quad$ молекулярная масса нефти, г/моль;

$T-\quad$ температура, $\mathrm{K}$;

$\mu_{\mathrm{H}}-\quad$ вязкость нефти при температуре Т, мПа с;

$V$ - $\quad$ мольный объем растворителя, мл/моль.

Молекулярную массу нефти можно найти из следующей корреляции [5]:

$$
M_{\mathrm{H}}=140,5+53,7 \cdot \ln \mu_{\mathrm{E} \Pi}-1,915 \cdot\left(\ln \mu_{\mathrm{E \Pi}}\right)^{2}
$$

$\mu_{\mathrm{r \Pi}}-$ динамическая вязкость нефти при температуре пласта, мПа с;

$M_{\text {н }}$ молекулярная масса нефти, г/моль. 
На основе второго закона Фика можно определить концентрацию растворителя в зависимости от расстояния до трещины при различной температуре и времени выдержки [7]:

$$
\frac{\partial C(x, t)}{\partial t}=D \frac{\partial^{2} C}{\partial x^{2}}
$$

$C(x, t)$ - концентрация растворителя на расстоянии от трещины $x$ в момент времени $t$ после начала процесса диффузии, д. ед.

Решением уравнения (5) относительно концентрации растворителя $C$ в зависимости от удаленности $x$ от трещины является:

$$
C(x, t)-C_{0}\left(1-\operatorname{erfc}\left(\frac{x}{2 \cdot(D t)^{0.5}}\right)\right)
$$

Как видно из рисунка 10 область проникновения растворителя сильно зависит от температуры пласта и времени выдержки. К примеру, для достижения оптимальной концентрации $15 \%$ и глубины проникновения 10 см сроки диффузионного обмена составляют менее 10 суток для температуры $100{ }^{\circ} \mathrm{C}$, а для пластовой температуры $28{ }^{\circ} \mathrm{C}-50$ суток. Таким образом можно определить необходимое время диффузионного обмена растворителя и сверхвязкой нефти в зависимости от температуры пласта.

С целью повышения эффективности применения растворителей для интенсификации добычи нефти необходимо вести его закачку с максимально возможным расходом и дальнейшей выдержкой на диффузионный обмен. Это позволит повысить глубину обработки в призабойной зоне пласта за счет конвективного механизма взаимодействия с нефтью, а для удаленной зоны пласта, в которой достичь высоких скоростей фильтрации невозможно - за счет диффузионных сил.

\section{Выводы}

1. Экспериментальным путем установлено, что расход закачиваемого в трещину карбонатной породы углеводородного растворителя влияет на коэффициент вытеснения сверхвязкой нефти. При малых скоростях закачки наблюдается процесс диффузионного вытеснения нефти, а при повешении расхода закачиваемого растворителя преобладает конвективный механизм вытеснения нефти. Данные механизмы были определены на основе экспериментальньх исследований, а также косвенно - на основе уточнения числа Пекле.

2. При повышении расхода закачиваемого растворителя увеличивается коэффициент вытеснения нефти, что можно объяснить увеличением глубины его проникновения за счет конвективных сил. Конечный коэффициент вытеснения нефти соответствовал $8 \%, 11,5 \%, 14 \%$ и 16\% при температурах 28,50 , 75 и $100^{\circ} \mathrm{C}$. 
3. Установлено, что холодная закачка растворителя в карбонатную породу трещинного типа малоэффективна и требует значительного количества времени для диффузионного обмена растворителя и нефти. К примеру, для достижения оптимальной концентрации $15 \%$ и глубины проникновения 10 см сроки диффузионного обмена составляют менее 10 суток для температуры $100{ }^{\circ} \mathrm{C}$, а для пластовой температуры $28^{\circ} \mathrm{C}-50$ суток. Таким образом можно определить необходимое время диффузионного обмена растворителя и сверхвязкой нефти в зависимости от температуры пласта.

4. Высокое пластовое давление изучаемого объекта ограничивает процесс парообразования растворителя, в результате нецелесообразно применение только дорогостоящих, легкокипящих алифатических растворителей.

5. Для изучаемого объекта предпочтительнее закачивать комплексные растворители, в составе которых должны быть ароматические углеводороды с концентрацией не менее $20 \%$. Закачка только лёгких углеводородных растворителей алканового ряда может вызвать осаждение тяжельх углеводородов из нефти.

\section{Библиографический список}

1. Bayestehparvin B., Ali S.M.F., Abedi J. Solvent-Based and SolventAssisted Recovery Processes: State of the Art// SPE EOR Conf. Oil Gas West Asia. 2018. № 03. P. 1-21.

2. ASTM 2042. Standard Test Method for Solubility of Asphalt Materials in Trichloroethylene; ASTM International, West Conshohocken, PA. 1997.

3. Cinar Y., Alhamdan M.R. Gravity drainage effects on compositional displacements in fractured reservoirs // SPE Middle East Oil Gas Show Conf. held Manama, Bahrain. 2015.

4. Cronin M., Emami-Meybodi H., Johns R.T. Diffusion-Dominated Proxy Model for Solvent Injection in Ultra-Tight Oil Reservoirs /I SPE Improv. Oil Recover. Conf. 14-18 April. Tulsa, Oklahoma, USA. 2018

5. Clossman P.J., Seba R.D. A correlation of viscosity and molecular weight // J. Can. Pet. Technol. 1990.

6. Алексеев С.Г. и др. Методы оценки взрывоопасности топливовоздушных смесей на примере керосина марки РТ. IV. ГОСТ P 12.3.047-98 // Пожаровзрывобезопасность. 2012. Т. 21, № 6.

7. Рудобашта С.П., Карташов Э.М. Диффузия в химико-технологических процессах. М.: Химия, 1993. 208 с

\section{References}

1. Bayestehparvin B., Ali S.M.F., Abedi J. Solvent-Based and SolventAssisted Recovery Processes: State of the Art// SPE EOR Conf. Oil Gas West Asia. 2018. № 03. P. 1-21. 
2. ASTM 2042. Standard Test Method for Solubility of Asphalt Materials in Trichloroethylene; ASTM International, West Conshohocken PA. 1997.

3. Cinar Y., Alhamdan M.R. Gravity drainage effects on compositional displacements in fractured reservoirs // SPE Middle East Oil Gas Show Conf. held Manama, Bahrain. 2015.

4. Cronin M., Emami-Meybodi H., Johns R.T. Diffusion-Dominated Proxy Model for Solvent Injection in Ultra-Tight Oil Reservoirs // SPE Improv. Oil Recover. Conf. 14-18 April. Tulsa, Oklahoma, USA. 2018.

5. Clossman P.J., Seba R.D. A correlation of viscosity and molecular weight // J. Can. Pet. Technol. 1990.

6. Alekseev S.G. i dr. Metody ocenki vzryvoopasnosti toplivovozdushnyx smesej na primere kerosina marki RT. IV. GOST R 12.3.04798 // Pozharovzryvobezopasnost. 2012. t. 21, № 6 (in Russ).

7. Rudobashta S.P., Kartashov E.M. Diffuziya $\vee$ ximiko-texnologicheskix processax. M.: Ximiya, 1993. 208 p. (in Russ).

Рукопись потупила в редакцию 12.01.19, принята к публикации 01.03.19

\section{6 авторах}

Шарифов Анар Рабилович, аспирант кафедры разработки и эксплуатации нефтяных и газовых месторождений Санкт-Петербургского горного университета. ScopusID: 57200435965

Email: anarshar@mail.ru.

Мардашов Дмитрий Владимирович, доцент кафедры разработки и эксплуатации нефтяных и газовых месторождений Санкт-Петербургского горного университета. ScopusID: 55596392500.

Email: Mardashov_DV@pers.spmi.ru.

\section{About the authors}

Sharifov Anar Rabilovich, PhD student of the Department of development and operation of oil and gas fields Saint Petersburg mining university. ScopusID: 57200435965 :

Email: anarshar@mail.ru

Mardashov Dmitriy Vladimirovich Associate Professor of the Department of development and operation of oil and gas fields Saint Petersburg mining university ScopusID: 55596392500

Email: Mardashov_DV@pers.spmi.ru. 